\title{
Genotyping of Individually Isolated gametes from Gossypium hirsutum Chromosome Substitution Lines
}

\section{Ahmad Naseer Aziz*, Abdul Mujeed Yakubu and Sherya Singh Hamal}

Department of Agricultural and Environmental Sciences, Tennessee State University, Nashville, TN, USA

\begin{abstract}
As an important crop for US agricultural security and sustainable agriculture, cotton genetic improvement requires development of innovative analytical tools. Genetic analyses based on individual gametes provide severa advantages including minimum sample requirement, genetic identification of male parent and overcoming the complexity of polyploidy due to haploid nature of microspores. This research used tetraploid cotton ( $G$. hirsutum $x$ G. barbadense) chromosome substitution (CS) lines with G. barbadense chromosomes 17 and 25 in $G$. hirsutum background. The individually isolated pollen grains were germinated to release their DNAs and genomic DNA was increased by modified primer extension pre-amplification (PEP) using MasterAmp ${ }^{\text {TM }}$ Extra-Long PCR Kit (EPICENTRE®, Madison, WI). Also from select cotton lines, microspores just released from tetrad developmental stage were individually isolated and gamete DNA was extracted as well as amplified through multiple displacement amplification (MDA) using REPLI-g Single Cell Kit (QIAGEN, Valencia, CA). The parental samples along with PEP and MDA amplified individual gamete DNAs were then analyzed using simple sequence repeat (SSR) as well as IRD800 and IRD-700 labeled (Li-Cor, Lincoln, NE) amplified fragment length polymorphism (AFLP) methods. Nineteen SSR and 28 AFLP primer pairs were used to analyze TM-1, 3-79, CS-B17 and CS-B25 cotton lines. The amplification of parental SSR and AFLP markers from both mature pollen as well as early free microspore samples provided unique tools for comparative genetic studies using agarose and polyacrylamide gel electrophoresis, respectively.
\end{abstract}

Keywords: Cotton pollen; Free (uninucleate) microspores; Chromosome substitution lines; SSR; AFLP; Primer extension preamplification; Multiple displacement amplification

Abbreviations: SSR: Simple Sequence Repeats; AFLP: Amplified Fragment Length Polymorphism; PEP: Primer Extension Preamplification; MDA: Multiple Displacement Amplification

\section{Introduction}

The segregation of parental markers, during anthesis, into its pollen grains can be used by plant breeders for genetic analyses. Gametes can be a convenient source of DNA as only limited freezer storage space is required for their use. DNA markers' based analyses of individual gametes has several downstream uses in plant breeding and genetic improvement applications [1]. Plant gametes also contain several organelles which contribute to markers' amplification products $[2,3]$. Therefore, such molecular markers could also be used to study the inheritance of organelles. Determining parental or recombinant genotypes of gametes for genetic mapping [4] is efficient and costeffective approach [5] through circumventing the need of large breeding populations for linkage analyses. To extract DNA from pollen grains, drilling a hole in the wall through a UV-laser microbeam have been reported [6]. Alternatively some isolated pollen grains can be germinated to release their cell contents [7].

Microsporogenesis stages can allow the isolation of free microspores (immediately after the tetrad separation) when their tectum formation is discontinuous and before the initiation stage of endexine development $[8,9]$. Such microspores can easily be lysed with reagents used for DNA extractions from animal cells that only have cell membranes [10]. Though individually isolated gametes have sufficient DNA for PCR amplification [11], the restriction enzyme based markers' analyses would require this amount to be pre-amplified [4]. Primer extension pre-amplification (PEP) protocol [12] and multiple displacement amplification (MDA) [10] have been used to increase the amount of genomic DNA of a single cell sample. DNA fingerprinting methods can be used to identify the genetic make-up of plants and are very useful for true-to-type identification and reduce development costs and time required for the evaluation of crosses [13-15].

Amplified fragment length polymorphism (AFLP) being one of the popular genotyping tools [16] was used to demonstrate our approach. Another set of markers used in this study were simple sequence repeats (SSR) based, which have been found useful for genome wide coverage in cotton [17]. Analyses of molecular markers from individual gametes can generate genetic data without the need of performing controlled pollinations and/or maintaining large population for plant breeding $[6,11]$. The objectives of this research were to amplify the isolated individual gamete genomes of CS-B17 and CS-B25 breeding lines of Upland cotton [18], for subsequent genetic characterization. The chromosome substitution (CS) lines are nearly isogenic to the common parent TM-1 (Gossypium hirsutum) for 25 chromosome pairs except the pair of the substituted chromosome from the 3-79 (G. barbadense) [18]. The single mature pollen as well as free uninucleate microspores' genotyping protocols reported in this paper can serve as important tools for enhancing breeding efficiencies in cotton.

\section{Materials and Methods}

\section{Plant materials}

Upland cotton substitution lines, with most of the genome from

*Corresponding author: Ahmad Naseer Aziz, Department of Agricultural and Environmental Sciences, Tennessee State University, TN, USA, Tel: +1 615963-5000; E-mail: aaziz@tnstate.edu

Received December 05, 2017; Accepted December 21, 2017; Published December 27 , 2017

Citation: Aziz AN, Yakubu AM, Hamal SS (2017) Genotyping of Individually Isolated gametes from Gossypium hirsutum Chromosome Substitution Lines. Single Cell Biol 6: 169. doi:10.4172/2168-9431.1000169

Copyright: ( 2017 Aziz AN, et al. This is an open-access article distributed under the terms of the Creative Commons Attribution License, which permits unrestricted use, distribution, and reproduction in any medium, provided the original author and source are credited. 
G. hirsutum TM-1 while substituting chromosomes number 17 and 25 from $G$. barbadense double haploid line 3-79, were developed by Dr. Saha and others [18]. CS-B17 and CS-B25 were grown in the greenhouse using standard nursery gallons (4.5 litre) that contained Miracle-Gro Potting Mix (Scott Co., Marysville, OH). Plants were maintained in a glasshouse at $24^{\circ} \mathrm{C}$ to $28^{\circ} \mathrm{C}$, watered as needed and fertilized bimonthly with 0.21-0.07-0.14 (N-P-K) $\left(\mathrm{mgl}^{-1}\right)$ soluble fertilizer (Grace Horticultural Products Co., Cambridge, MA). DNA from leaf samples were extracted using DNeasy Plant Mini Kit (Qiagen, Santa Clara, CA) and grinding matrix along with Bio Fast Prep System (Q. Biogene, Irvine, CA), verified in a $2 \%$ agarose gel and quantified using a NanoDrop 1000 Spectrophotometer (Thermo Fisher Scientific, Wilmington, DE). DNA gels were photographed using an AlphaImager 2000 System (Alpha Innotech, San Leandro, CA).

\section{Individual pollen DNA release and pre-amplification}

From mature flowers, pollen grains were harvested and then individually isolated [11] using Austerlitz insect pin (Nasco, Fort Atkinson, WI, size 00, $37 \mathrm{~mm}$ long) mounted on an ultrafine move Marzhauser (HS-6) micromanipulator (ALA Scientific Instruments, Inc., Westbury, NY). Each grain was thus placed in a separate PCR (polymerase chain reaction) tube that contained $5 \mu \mathrm{l}$ of pollen germination media consisting of $25 \%(\mathrm{w} / \mathrm{v})$ sucrose, $0.52 \mathrm{~mm} \mathrm{KNO}$, $3.06 \mathrm{~mm} \mathrm{MnSO}_{4}, 1.66 \mathrm{~mm} \mathrm{H}_{3} \mathrm{BO}_{3}, 0.42 \mathrm{mM} \mathrm{MgSO}_{4}$ and $1 \mu \mathrm{M}$ gibberellic acid, pH 7.6. Following the protocol of Aziz and Sauve [4], isolated pollen grains in the individual PCR tubes were germinated for 1-2 hours at room temperature to release their DNA. This DNA was amplified via MasterAmp $^{\text {mw }}$ Extra-Long PCR kit (EPICENTRE ${ }^{\oplus}$, Madison, WI) with an array of continuous random 15-mer primers (Operon Technologies, Alameda, CA) using the primer extension pre-amplification (PEP) protocol of Zhang et al. [12]. Amplification of pollen DNA via the PEP procedure resulted in many genomic copies distributed in fragments of varied lengths. Pollen PEP-DNA products were visualized on $2 \%$ agarose gel after staining with ethidium-bromide and purified using the DNeasy ${ }^{\oplus}$ Plant Mini Kit (QIAGEN, Valencia, CA).

\section{Individual microspore isolation for DNA extraction}

The anthers from immature flower were identified to capture microspores immediately after the tetrad stage of development. Such microspores (without mature cell wall) were individually isolated from aqueous (27\% D-sorbitol) spread on a glass slide with the aid of CellTram Manual Micro-injector (Eppendorf North America, Hauppauge, NY) mounted over a UMMJ-3FC micromanipulator (Narishige International USA, Amityville, NY). The micro-injector was used as a fluid control device for aspirating, holding and disposing microspores from micro-capillary tube through sensitive manual control (Figure 1).

The individual microspores, in about $1 \mu \mathrm{l}$ of $27 \% \mathrm{D}$-sorbitol, were dispensed in PCR tubes containing $3.5 \mu \mathrm{l}$ of phosphate buffer saline (PBS) solution. Multiple displacement amplification (MDA) through REPLI-g Single Cell Kit (QIAGEN, Valencia, CA) was used to lyse isolated individual microspores and increase their DNA's. The $40 \mu \mathrm{l}$ of MDA reaction mixture containing $29 \mu \mathrm{l}$ reaction buffer, $9 \mu \mathrm{l} \mathrm{H}_{2} \mathrm{O}$ and 2 $\mu \mathrm{l}$ enzyme (QIAGEN) was added to the PCR tubes containing individual microspore in $27 \% \mathrm{D}$-sorbitol and PBS solution. The tubes were then incubated at $30^{\circ} \mathrm{C}$ for eight hours and MDA products were quantified using a Nano drop spectrophotometer (Eppendorf North America).

\section{Amplification and scoring of SSR markers}

The amplification protocols for microsatellite markers in presence of Gotaq ${ }^{\circ}$ green master mix (part \# 9PIM712, Promega Corporation,

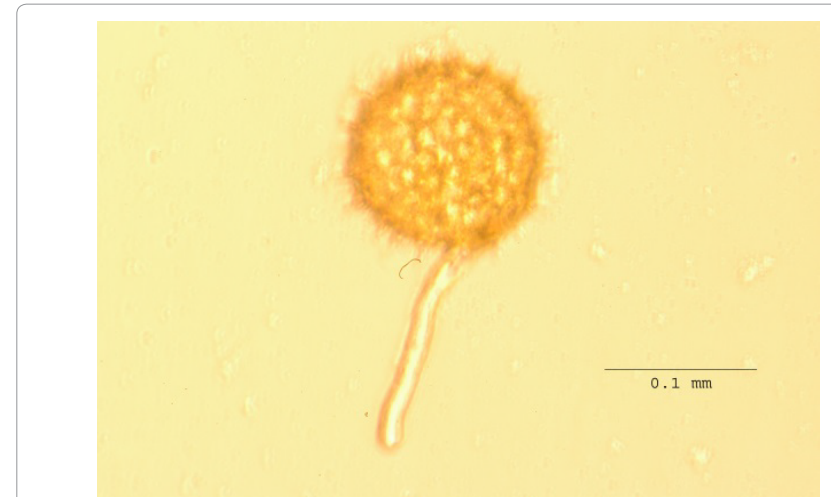

Figure 1: Opening of individual cotton pollen wall in the germination medium (25\% (w/v) sucrose, $0.52 \mathrm{mM} \mathrm{KNO}_{3}, 3.06 \mathrm{~mm} \mathrm{MnSO}, 1.66 \mathrm{~mm} \mathrm{H}_{3} \mathrm{BO}_{3}, 0.42$ $\mathrm{mm} \mathrm{MgSO}$ and $1 \mu \mathrm{M}$ gibberellic acid, $\mathrm{pH} \mathrm{7.6)} \mathrm{to} \mathrm{release} \mathrm{its} \mathrm{DNA} \mathrm{for} \mathrm{subsequent}$ amplifications and restriction digest.

\begin{tabular}{|c|c|c|}
\hline SSRs & Upstream (5') primer & Downstream (3') primer \\
\hline BNL0891 & TTTTCAGCTGGAGATGTGCT & СТTCAАAАТССАСТGССТСА \\
\hline BNL1404 & CGAGAGCCCACTAACAGAAA & CCATTTGTTTTTTCCCCCTT \\
\hline BNL1667 & AGGTGCTTCAGGCATGATTC & СССТСАСАССТАААСССААА \\
\hline BNL2717 & CCTTGCTAGCCAAAGCAGAC & ССTCCATGAAAGGTGCAATT \\
\hline BNL3103 & $\begin{array}{l}\text { ACTTTGAGATATTGTTATTC- } \\
\text { TACCCG }\end{array}$ & $\begin{array}{c}\text { TCGAACAATTACGAAT- } \\
\text { CAAATG }\end{array}$ \\
\hline BNL3449 & AAGCTGTGGCTATGATGCCT & $\begin{array}{l}\text { AGAGCAAAAAACAATTA- } \\
\text { CAAAAGC }\end{array}$ \\
\hline BNL3371 & CAATCCTTTACGTGGCCTGT & AAAGACAGGCAATCCCCTTT \\
\hline BNL3479 & AGTGGGTTGGACTTTCATGC & CACGGGCTTTTTTTTTTTTCA \\
\hline BNL3971 & CACATATTTTTGCCTCACGC & TGTGGACCCAAAAAGGAAGA \\
\hline BNL4059 & GAGTTACGCCTGGCAATCAT & CCATCCCCAGTGGTGTTATC \\
\hline GH537 & $\begin{array}{l}\text { GTTGGGTGGCAAT- } \\
\text { TCCTTTTAGATC }\end{array}$ & $\begin{array}{c}\text { AAAGCTAATC- } \\
\text { CCTATACCTTTTCTTCG }\end{array}$ \\
\hline JESPR0204 & CTCCAGGTTCAATGGTCTG & GCCATGTTGGACAAGTAGTC \\
\hline MUSB0606 & TGCCATGGCTTATAAATGAGG & $\begin{array}{c}\text { CCAAGAAAAGGGGACTA- } \\
\text { AATTG }\end{array}$ \\
\hline NAU3093 & GTCTTGAACCGGAACTTGAT & TCCTGTTGAACACCAAAGTG \\
\hline NAU3306 & ACAACCCAAGAGGACAAAGA & ATAACCACAGCGACCACTTT \\
\hline NAU3680 & GGAATTAACGGAATGGTGAG & TTTGCTTGAGGAAATTAGGG \\
\hline NAU3684 & TCCATTTGTCCCTTGAATCT & CAGTGACCATTGATGAAGGA \\
\hline NAU5236 & TTCAAGTGTCGACCATCAAC & AGGGGTGACTAAGATGGTGA \\
\hline NAU6542 & GTTCCCTTTTCGTTTTGGTT & GAGCATGTTGCAATGAGAAC \\
\hline
\end{tabular}

Table 1: Simple Sequence Repeat (SSR) primer pairs designed by Alfred et al. [19], Jiwen et al. [20], Zhang et al. [21] and Yu et al. [22], were used in genetic analyses of TM-1 (G. hirsutum), 3-79 (G. barbadense) and chromosome substitution lines CS-B17 and CS-B25 (Upland cotton chromosome 17 and 25 substituted with that of Pima cotton, respectively) lines

Madison, WI) were used for the production of SSR based markers. The 54 mapped SSRs which have been reported for cotton lines with $G$. hirsutum and G. barbadense backgrounds [19-22], were initially selected for this study. After further screening 19 SSR primer pairs in Table 1 were used to analyze TM-1, 3-79, CS-B17 and CS-B25 cotton lines. The polymerase chain reactions (PCR) contained $1 \mathrm{X}$ Gotaq ${ }^{\circ}$ green master mix, nuclease-free water (Promega Corporation), $1 \mathrm{M}$ each of the forward and reverse primers (Integrated DNA Technologies, Coralville, IA) and $100 \mathrm{ng}$ DNA template. After initial denaturation at $95^{\circ} \mathrm{C}$ for two minutes, the amplification reactions were subjected to 35 cycles of $94^{\circ} \mathrm{C}$ for $30 \mathrm{sec}, 55^{\circ} \mathrm{C}$ for $4 \mathrm{sec}, 72^{\circ} \mathrm{C}$ for $1 \mathrm{~min}$ before final extension at $72^{\circ} \mathrm{C}$ for $10 \mathrm{~min}$, and subsequent soak at $10^{\circ} \mathrm{C}$. The amplified SSRs were then resolved through $2.5 \%$ agarose gel electrophoresis in the presence of a minimum 5X GelRed ${ }^{\mathrm{TM}}$ (Biotium, Hayward, CA) DNA stain and photographed on an ultra-violet illuminator. 


\section{Identification and analyses of AFLP markers}

AFLP markers were generated from parental leaf DNA and pollen PEP products using AFLP Analysis System I Kit of Invitrogen Life Technologies $^{\mathrm{TM}}$ (Carlsbad, CA) in the presence of fluorescent Li-Cor (Inc., Lincoln, NE) IRDye ${ }^{\oplus}$ Phosphoramidite (IRD)-700 and IRD-800 (optimized for Li-Cor $700 \mathrm{~nm}$ and $800 \mathrm{~nm}$ infrared channels) labeled primers designed for EcoRI adaptors. Before analyses on sequencing gel, $3 \mathrm{X}$ blue loading dye (Li-Cor) was added to the AFLP samples. As described earlier [5], the AFLP profiles from parent and from each pollen DNA sample $(\sim 0.6 \mu \mathrm{l})$ were separated through electrophoresis on a DNA sequencer using denaturing $6.5 \%$ polyacrylamide gel between $25 \mathrm{~cm}^{2}$ Starphire glass plates. These DNA bands were scored, by simultaneously electrophoresing and analyzing the selective amplification products for approximately 3.5 hours, on an automated DNA analyzer (Global 4300 DNA Analyzer and Sequencer, LI-COR, Lincoln, NE). The Saga ${ }^{\mathrm{TM}}$ Generation 2 Version 3.1 (Li-Cor, Lincoln, NE) software was used for maintaining constant electrophoresis conditions of $1500 \mathrm{~V}, 40 \mathrm{~W}$ and $40 \mathrm{~mA}$ at $45^{\circ} \mathrm{C}$ as well as scoring AFLP markers and adding the markers' information to a database (Oracle ${ }^{\circledR} 9 \mathrm{i}$ ) for generating reports toward data export.

\section{Results}

\section{Whole genome amplification from pollen and microspores}

Molecular markers' based assays of individual cotton pollen grains were possible after the collection of isolated pollen gains via micromanipulation [11] and DNA extraction using pollen germination protocol (Figure 1). The small amount of DNA in an individual pollen grain was increased by using the primer-extension pre-amplification (PEP) procedure. The enhancers in the MasterAmp ${ }^{\text {Tx }}$ Long PCR kit $\left(\right.$ EPICENTRE $^{\star}$ ) improve the fidelity and accuracy of the PEP products [23] which results in increased sizes and the numbers of the molecular markers in subsequent procedure [5]. Segments of cotton pollen genome was amplified resulting in many genomic copies distributed in fragments of varied lengths that appeared as a smear of larger than $2000 \mathrm{bp}$ on the DNA gel (Figure 2). After initial experiments with nine formulations of Master Amp ${ }^{\text {Tx }}$ Long PCR kit, PreMix-3 and PreMix-9 (EPICENTRE ${ }^{\bullet}$ ) were selected for all pollen DNA (whole genome) amplifications using the PEP procedure. Pollen grains were individually isolated in PCR tubes and germinated for PEP amplifications of whole genomes. The

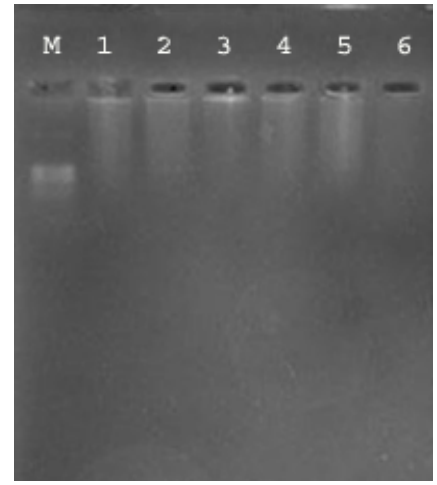

Figure 2: Whole genome amplified as fragments from individually isolated cotton pollen grain after using MasterAmp ${ }^{\mathrm{TM}}$ Extra-Long PCR kit (EPICENTRE $囚$, Madison, WI) along with an array of continuous random 15-mer primers (Operon Technologies, Alameda, CA) during Primer Extension Pre-amplification procedure. The CS-B17 (Upland cotton line with chromosome 17 substituted with that of Pima cotton) pollen DNA fragments appearing as smears (Lanes 1 to 6) larger than 2000 base-pairs (bp) DNA marker (lane M) of a low scale 100 bp Ladder (Thermo Fisher Scientific Inc., Waltham, MA).

\begin{tabular}{|c|c|c|}
\hline AFLP Primer pairs & Labelling dye & Cotton lines genotyped \\
\hline E-AAC/M-CAG & IRDye® 700 & TM-1, 3-79 and CS-B17 \\
\hline E-AAG/M-CAA & IRDye® 800 & TM-1, 3-79 and CS-B17 \\
\hline E-AAG/M-CTT & IRDye® 700 & TM-1, 3-79 and CS-B17 \\
\hline E-ACA/M-CAA & IRDye® 700 and 800 & TM-1, 3-79 and CS-B17 \\
\hline E-ACA/M-CAC & IRDye $\circledast 800$ & TM-1, 3-79 and CS-B17 \\
\hline E-ACA/M-CAT & IRDye® 700 & TM-1, 3-79 and CS-B17 \\
\hline E-ACA/M-CTA & IRDye® 700 & TM-1, 3-79 and CS-B17 \\
\hline E-ACA/M-CTC & IRDye ${ }^{8} 700$ & TM-1, 3-79 and CS-B17 \\
\hline E-ACT/M-CAA & IRDye ${ }^{\circledR} 700$ & TM-1, 3-79 and CS-B17 \\
\hline E-ACT/M-CAC & IRDye® 700 and 800 & TM-1, 3-79 and CS-B17 \\
\hline E-ACT/M-CAG & IRDye $\circledast 700$ & TM-1, 3-79 and CS-B17 \\
\hline E-ACT/M-CAT & IRDye® 700 and 800 & TM-1, 3-79 and CS-B17 \\
\hline E-ACT/M-CTA & IRDye® 700 and 800 & TM-1, 3-79 and CS-B17 \\
\hline E-ACT/M-CTC & IRDye® 700 and 800 & TM-1, 3-79, CS-B17 and CS-B25 \\
\hline E-ACT/M-CTG & IRDye® 700 and 800 & TM-1, 3-79, CS-B17 and CS-B25 \\
\hline E-ACT/M-CTT & IRDye $\AA 800$ & TM-1, 3-79, CS-B17 and CS-B25 \\
\hline E-ACC/M-CAT & IRDye® 700 & TM-1, 3-79 and CS-B17 \\
\hline E-ACC/M-CTA & IRDye ${ }^{\circledR} 800$ & TM-1, 3-79 and CS-B25 \\
\hline E-ACC/M-CTC & IRDye® 700 and 800 & CS-B17 and CS-B25 \\
\hline E-ACG/M-CAG & IRDye ${ }^{2} 700$ & TM-1, 3-79 and CS-B25 \\
\hline E-ACG/M-CAT & IRDye® 700 & TM-1, 3-79, CS-B17 and CS-B25 \\
\hline E-AGC/M-CAA & IRDye $® 700$ and 800 & TM-1, 3-79, CS-B17 and CS-B25 \\
\hline E-AGC/M-CAC & IRDye® 700 and 800 & TM-1, 3-79, CS-B17 and CS-B25 \\
\hline E-AGC/M-CAG & IRDye® 700 & TM-1, 3-79 and CS-B17 \\
\hline E-AGC/M-CAT & IRDye® 700 & TM-1, 3-79 and CS-B17 \\
\hline E-AGG/M-CAA & IRDye ${ }^{\circledR} 700$ & TM-1, 3-79 and CS-B17 \\
\hline E-AGG/M-CAC & IRDye® 700 & TM-1, 3-79 and CS-B17 \\
\hline E-AGG/M-CAT & IRDye $® 700$ & TM-1, 3-79 and CS-B17 \\
\hline
\end{tabular}

Each AFLP (amplified fragment length polymorphism) marker is identified by the primer-pair designed for both EcoRI (E) and Msel (M) adaptors, and the three selective nucleotides of each primary Primers designed for EcoRI adaptors had been labelled by Li-Cor (Inc., Lincoln, NE) IRDye ${ }^{\circledR}$ Phosphoramidite florescent dyes optimized for Li-Cor $700 \mathrm{~nm}$ (IRD-700) or $800 \mathrm{~nm}$ (IRD-800) infrared channels.

Table 2: Amplified fragment length polymorphism (AFLP) primer pairs for genetic analyses of G. hirsutum CS-B17 and CS-B25 lines.

individual microspores, when treated with REPLI-g Single Cell Kit (QIAGEN) release genomic DNAs for subsequent amplifications [9]. All individually isolated cotton early free microspores released their contents giving adequate yields of amplified DNA products through multiple displacement amplification (MDA) technology. The REPLI-g (QIAGEN) pre-amplified DNA concentrations from the individual microspores of cotton lines ranged from 1627 to $3900 \mathrm{ng} / \mu \mathrm{l}$ with good purity (UV260/280 absorbance values of 1.6 to 1.8 ). This is a first report on direct analyses of cotton microspores that allows the genetic assessments of entire (100\%) gamete population while avoiding any segregation distortion of parental markers in subsequent analyses.

\section{SSR and AFLP markers for CS-B17 and CS-B25 lines}

The selected SSR primer pairs amplified the microsatellite markers of expected 150-300 bp sizes from TM-1, 3-79, CS-B17 and CS-B25 cotton lines, confirming the reports of the previous [20,22,25-28]. Based on the smaller size of the amplicon and good band intensity, 10 of the 19 SSR primer pairs were used for subsequent gamete DNA analyses. AFLP analyses of TM-1, 3-79, CS-B17 and CS-B25 parental tissues revealed that 28 florescent labelled (Li-Cor, Inc.) primer pairs (Invitrogen Life Technologies) were suitable for fingerprinting these lines (Table 2).

Each AFLP marker was designated by the DNA product size (bp) as well as primer pair along with the labelling IRD dye (700 or 800 ). 
The IRDye 700 and 800 infrared dyes' labeling (incorporation of dye molecules) of E-primers has been reported to alter their annealing to templates [29-31], therefore, some amplified products in this study were found to be different in size than previous reports. The uses of labelled primers for comparative AFLP profiling of genomes helps the automated analyses, but these should be adopted after standardizing the protocols with each labeling dye. Ten primer pairs (E-ACA/M-CAA, E-ACT/M-CAC, E-ACT/M-CAT, E-ACT/M-CTA, E-ACT/M-CTC, E-ACT/M-CTG, E-ACC/M-CTA, E-ACC/M-CTC, E-AGC/M-CAA, and $\mathrm{E}-\mathrm{AGC} / \mathrm{M}-\mathrm{CAC}$ ) amplified AFLPs when these E-primers were labelled either IRDye 700 or 800 infrared dye. The IRDye 800 labelled E-ACT contributed in AFLP amplifications in combination with all eight unlabeled M-primers. The unlabeled M-CAT primer was compatible with six E- primers (identified by the three selective nucleotides: ACA, ACC, ACG, ACT, AGC, and AGG) for AFLP markers' amplifications from TM-1, 3-79, CS-B7 and CS-B5 cotton lines. Confirming the efficiency of AFLP markers' production rates reported earlier [14], on average each of the 28 primer pairs used produced six scorable AFLPs.

\section{SSR and AFLP Analyses of individual gametes from cotton lines}

CS-B17 and CS-B25 single cell whole genome amplification products were subjected to SSR and AFLP analyses for confirming the detection of parental cotton DNA-markers in isolated individual cotton gametes. DNAs of minimum five individual pollen grains from CS-B17 and CS-B25, which were successfully amplified via PEP procedure, became selected for subsequent SSR and AFLP analyses. Also minimum five microspores from TM-1, 3-79 and CS-B17 cotton lines were subjected to SSR analyses after MDA procedure. Only a limited number of parental SSR and AFLP markers could be scored from gamete samples since only those parental markers were amplifiable that had primer annealing sites available in fragmented DNA samples (PEP/ MDA products) pre-amplified from single cells (Figure 2).
Six parental SSRs (BNL1667, BNL3479, BNL3971, NAU3093, NAU3684 and NAU5236) were demonstrated for CS-B17 gametes and 10 parental SSRs (BNL1404, BNL1667, BNL2717, BNL3471, BNL3971, NAU3093, BNL4059, NAU3306, NAU3684 and NAU5236) were confirmed in CS-B25 pollen samples. As expected for a near isogenic line [32], parental DNA-markers did not segregate in the microspores of the CS-B17 cotton line while some TM-1 and 3-79 microspores showed different sized SSRs than that of parent (Figure 3).

Over 80 parental AFLP's were analysed for their presence in $G$. hirsutum CS-B17 and CS-B25 pollen grains. PEP amplification protocol resulted in sufficient DNA from each pollen grain for subsequent restriction digestion needed in dual dye based AFLP analyses, and amplified many larger ( $>250$ base pairs) selective markers. Lack of segregation of either TM-1 or 3-79 relevant AFLPs in CS-B17 and CSB25 pollen demonstrated the near-isogenic nature of these two progeny lines (Figure 4).

\section{Discussion}

The PEP and MDA mediated whole genome amplifications allowed subsequent detection of genetic markers from an individual pollen grain and microspore. From individually isolated pollen grains for PEP amplifications, only about $60-70 \%$ are usually successfully germinated for subsequent DNA analyses [4]. Since only responsive gametes are available for DNA amplifications through anther-culture and pollengermination approaches, both methods cause segregation distortion and bias in genetic analyses [24]. The individual microspores on the other hand are expected to give $100 \%$ success rate, when treated with REPLI-g Single Cell Kit (QIAGEN) to extract and amplify genomic DNAs [9], thus were also used in this study. Through subsequent DNA amplifications, this report demonstrated the isolation of free microspores when tectum formation is either discontinuous or before the initiation
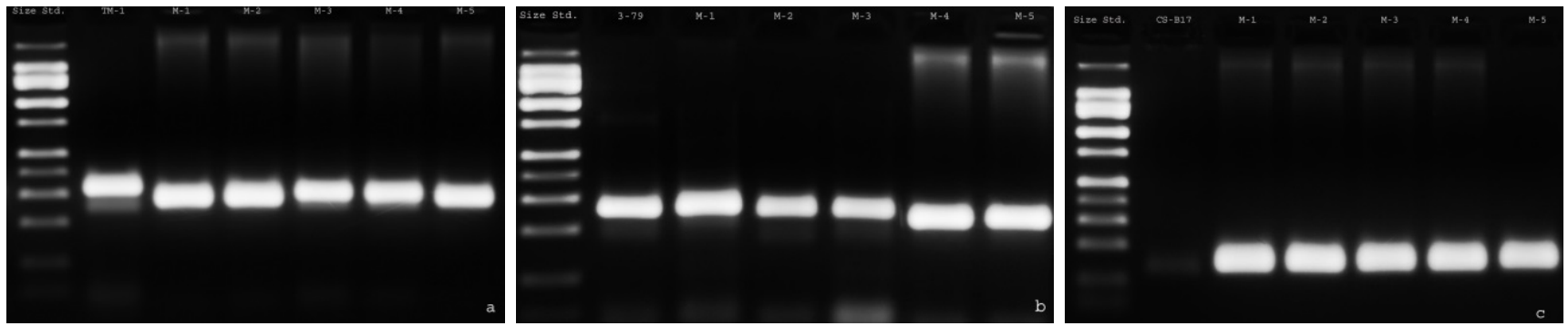

Figure 3: Amplification of Simple Sequence Repeat (SSR) markers from cotton leave tissues of TM-1, 3-79 and CS-B17 (Upland cotton line with chromosome 17 substituted with that of Pima cotton) as well as pre-amplified DNAs of five individually isolated pollen grains of TM-1, 3-79 and CS-B17 (lanes M-1 to M-5). Amplification reactions were subsequent resolved through agarose (2.5\%) gel electrophoresis along with 50-2000 bp DNA size ladder (Fisher BioReagents ${ }^{\mathrm{TM}}$, Pittsburgh, PA). (a) TM-1 leaves and microspores amplified with NAU3684, (b) 3-79 leaves and microspores amplified with BNL3479, (c) CS-B17 with BNL3971.

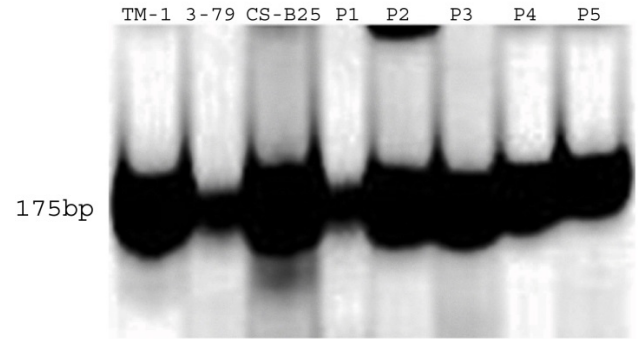

Figure 4: Amplification of AFLP (amplified fragment length polymorphism) markers from pre-amplified DNAs of individually isolated pollen grains (lanes P1 to P5) of CS-B25 (Upland cotton line with chromosome 25 substituted with that of Pima cotton) and parental leave tissues (lanes TM-1, 3-79, CS-B25) with E-ACC/M-CTT primer pair where E-primer was labelled with Li-Cor's IRDye ${ }^{8} 800$, and subsequent analysis through sequencing gels on LI-COR's 4300 DNAAnalyzer and Sequencer (Li-Cor, Lincoln, NE). AFLP markers were amplified using primer-pairs designed for EcoRI (E) and Msel (M) adaptors and electrophoresed along with Li-Cor (Inc., Lincoln, NE) 50-700 base-pair DNA-band size standard. 
Citation: Aziz AN, Yakubu AM, Hamal SS (2017) Genotyping of Individually Isolated gametes from Gossypium hirsutum Chromosome Substitution Lines. Single Cell Biol 6: 169. doi:10.4172/2168-9431.1000169

Page 5 of 6

stage of endexine development [8,9]. Ability to individually analyze developing microspores provides unique tools for comparative genetic analyses in pollen populations. Since individual pollen and microspores have limited amounts of DNA, the respective methods tested in this study for the amplification of the single cell genome via PEP and MDA procedures will benefit the industry by reducing the costs of genetic analyses for gametic merit. The individual gamete procedures described in this study can also lead to replacing the need of creating mapping populations for linkage analyses. Li-Cor dual-dye based fragment analysis system, used in this study, has been found cost effective than three-florescent based dyes of Applied-Biosystem (Life Technologies) for the fragment based DNA analyses [5]. Among 28 AFLPs reported here, seven pairs (E-ACA/M-CTC, E-ACC/M-CAC, E-ACC /M-CAT, E-ACC /M-CTA, E-ACC /M-CTC, E-ACC /M-CTT and E-AGC/MCAT) have been previously used by other researchers [14]. IRDye ${ }^{\circ}$ 700 and 800 infrared dye labeling of E-primers has been reported to alter their annealing to templates [29-31]. Such incorporation of dye molecules to the seven primers used in this study, caused the amplified products to be of different sizes than previously reported. However, the efficiency of AFLP markers' production was found comparable with the rates reported earlier [14].

\section{Conclusion}

Homozygous CS-B17 and CS-B25 plants were used in this study, though residual effects of heterozygosity can exist from other gametes [32]. Also due to homeologous nature of individual gametes, single specific genes can be identified through these protocols due to existence of only one copy. With the linkage of SSR and AFLP markers to desirable traits, single cell genotyping and determining gamete merit could serve as important tools for enhancing the breeding efficiencies. The chromosomal assignments of the markers [32] and association of quantitative trait loci in cotton facilitate relating the phenotype to genotype for important agronomic traits [33]. These protocols developed for mature-pollen (viable fertilizations) as well as early-freemicrospores (total genome segregation studies) analyses would allow comparative genetic studies per gametic stage/frequency for different plant types.

\section{Acknowledgement}

Authors are very much obliged to Dr. Sukumar Saha (USDA-ARS, Genetics and Sustainable Agriculture Research Unit, MS, 39762) for sharing the seeds of cotton chromosomal lines used in this study. Authors would also like to thank Mr. Micheal Jenning, Ms. Andrea Sherrell, Mr. Toney Tillman, Ms. Christy Gibson and Mr. Deependra Bhatta for maintaining the experimental plants in the greenhouse and Ms. Vanaja Kankarla, Mr. Rickey Jackson, Ms. L. Sahithi Kommireddy and Mr. Girma Ayana for technical assistance. This work was supported by USDA/NIFA an Evans-Allen Grant to TSU's College of Agriculture, Human and Natural Sciences.

\section{References}

1. Hubert R, Weber JL, Schmitt K, Zhang L, Arnheim N (1992) A new source of polymorphic DNA markers for sperm typing: Analysis of microsatellite repeats in single cells. Am J Hum Genet 51: 985-991.

2. Desprez B, Chupeau Y, Bourgin JP (1995) Preparation and fusion properties of protoplasts from mature pollen of Nicotiana tabacum. Plant Cell Rep 14: 199203.

3. Petersen G, Johansen B, Seberg O (1996) PCR and sequencing from a single pollen grain. Plant Mol Biol 31: 189-191.

4. Aziz AN, Sauve RJ (2008) Genetic mapping of Echinacea purpurea via individual pollen DNA fingerprinting. Mol Breed 21: 227-232.

5. Aziz AN, Sauve RJ, Tegegne F (2007) Cost of AFLP-based-fingerprinting for phylo-genetic and genetic-linkage analyses for the purple coneflower, several St. john's wort and goldenseal accessions. Acta Hort 756: 85-94.

6. Matsunaga S, Schütze K, Donnison IS, Grant SR, Kuroiwa T, et al. (1999)
Single pollen typing combined with laser-mediated manipulation. Plant J 20 371-378.

7. Aziz AN (2014) Isolation and DNA-marker based genotyping of individual pollen grains. Pure Appl Biol 3: 107-114.

8. Wallace S, Fleming A, Wellman CH, Beerling DJ (2011) Evolutionary development of the plant spore and pollen wall. AoB Plants11: plr027.

9. Sharma A, Singh MB, Bhalla PL (2015) Ultrastructure of microsporogenesis and microgametogenesis in Brachypodium distachyon. Protoplasma 252 1575-1586.

10. Li X, Li L, Yan J (2015) Dissecting meiotic recombination based on tetrad analysis by single microspore sequencing in maize. Nat Commun 6: 6648

11. Aziz AN, Seabrook JEA, Tai GCC (1999) Amplification of RAPD markers from individual pollen grains of a diploid Solanum clone 9507-04. Amer J Potato Res 76: 179-182.

12. Zhang L, Cui X, Sciimitt K, Hubert R, Navidi W (1992) Whole genome amplification from single cell: Implications for genetic analysis. Proc Natl Acad Sci USA 89: 5847-5851.

13. Vos P, Zabeau M, Hogers R, Bleeker M, Reijans M, et al. (1995) AFLP: A new technique for DNA fingerprinting. Nucleic Acids Res 23: 4407-4414.

14. Myers GO, Jiang B, Akash MW, Badigannavar A, Saha S (2008) Chromosomal assignment of AFLP markers in upland cotton (Gossypium hirsutum L.) Euphytica 165: 391-399.

15. Gutie'rrez OA, Stelly DM, Saha S, Jenkins JN, McCarty Jr JC, et al. (2009) Integrative placement and orientation of non-redundant SSR loci in cotton linkage groups by deficiency analysis. Mol Breed 23: 693-707.

16. http://www.investigativegenetics.com/content/5/1/1

17. Yu JZ, Fang DD, Kohel RJ, Ulloa M, HinzeLL, et al. (2012) Development of a core set of SSR markers for the characterization of Gossypium germplasm. Euphytica187: 203-213.

18. Stelly DM, Saha S, Raska DA, Jenkins JN, McCarty JC, et al. (2005) Registration of 14 Upland (Gossypium hirsutum) germplasm lines disomic for different G. barbadense chromosome or arm substitutions. Crop Sci 45: 2663-2665.

19. Alfred Q, Liu HY, Xu HM, Li JR, Wu JG, et al. (2012) Mapping of quantitative trait loci for oil content in cotton seed kernel. J Genet 91: 289-295.

20. Jiwen Y, Shuxun Y, Shuli F, Meizhen S, Honghong Z, et al. (2012) Mapping quantitative trait loci for cottonseed oil, protein and gossypol content in a Gossypium hirsutum x Gossypium barbadense backcross inbred line population. Euphytica 187: 191-201.

21. Zhang T, Qian N, Zhu X, Chen H, Wang S, et al. (2013) Variation and transmission of QTL alleles for yield and fiber qualities in Upland cotton cultivars developed in China. PLoS One 8: e57220.

22. Yu J, Jung S, Cheng CH, Ficklin SP, Lee T, et al. (2014) CottonGen: genomics, genetics and breeding database for cotton research. Nucleic Acids Res 42: 1229-1236.

23. http://barnes1.wustl.edu/ wayne/faq.wpa/.

24. Tai GCC, Seabrook JEA, Aziz AN (2000) Linkage analysis of anther-derived monoploids showing distorted segregation of molecular markers. Theor Appl Genet 101:c126-130.

25. Reddy OUK, Pepper AE, Abdurakhmonov I, Saha S, Jenkins JN, et al. (2001) New dinucleotide and trinucleotide microsatellite marker resources for cotton genome research. J Cotton Sci 5: 103-113.

26. Frelichowski JE Jr, Palmer MB, Main D, Tomkins JP, Cantrell RG, et al. (2006) Cotton genome mapping with new microsatellites from Acala 'Maxxa' BACends. Mol Genet Genomics 275: 479-491.

27. Guo W, Cai C, Wang C, Han Z, Song X, et al. (2007) A microsatellite-based, gene-rich linkage map reveals genome structure, function and evolution in gossypium. Genetics 176: 527-541.

28. Hoffman SM, Kohel RJ, Pepper AE, Xiao J, Yu JZ, et al. (2007) Identification of 700 new microsatellite loci from cotton (G. hirsutum L.). J Cotton Sci 11 208-241.

29. Aziz AN (2008) IRD800 Fluorescent dye may alter AFLP primers' annealing in flowering cherries. South Nursery Assoc Res Conf Proc 53: 162-166. 
Citation: Aziz AN, Yakubu AM, Hamal SS (2017) Genotyping of Individually Isolated gametes from Gossypium hirsutum Chromosome Substitution Lines. Single Cell Biol 6: 169. doi:10.4172/2168-9431.1000169

Page 6 of 6

30. Masi P, Spagnoletti Zeuli PL, Donini P (2003) Development and analysis of multiplex microsatellite markers sets in common bean (Phaseolus vulgaris L.). Mol Breed 11: 303-313

31. Zhu Z, Waggoner AS (1997) Molecular mechanism controlling the incorporation of fluorescent nucleotides into DNA by PCR. Cytometry 28: 206-211.
32. http://www.intechopen.com/books/plant-breeding/chromosome-substitutionlines-concept-development-andutilization-in-the-genetic-improvement-of-upla.

33. Wang Z, Zhang D, Wang X, Tan X, Guo H, et al. (2013) A whole-genome DNA marker map for cotton based on the d-genome sequence of Gossypium raimondii L. G3 (Bethesda) 3: 1759-1767. 